\title{
From the Editors
}

We are so excited to present the inaugural issue of MUSIC.OLOGY.ECA. This has been an almost year-long project and while there have been a few bumps along the way, we are incredibly pleased with the result. The aim of the journal is to provide an opportunity for masters and early-stage $\mathrm{PhD}$ students doing research in music to have an opportunity to be published. From the start we wanted to create an interdisciplinary music research journal and are happy to say that this first issue includes essays by students across music, sound design, and Celtic studies! Each essay highlights aspects of music, while also interlacing the research with the home discipline.

The idea for MUSIC.OLOGY.ECA came - as many great ideas do - during an evening at the pub. We had just finished our first few weeks of classes and having attended the Samson Young/Real Music exhibition at the Talbot Gallery (an amazing example of music and art working together to create a cohesive front), we settled into Drummond Street's Brass Monkey. We were chatting about ideas for the year ahead and felt inspired to create a platform where students could share interdisciplinary music research that would be easy enough to understand for people outside the music discipline.

As the year progressed, the shape and format of the journal changed, but the concept stayed largely the same.

We were lucky enough to have guidance and support from the faculty Reid School of Music and, in particular, the MMus Musicology Programme Director, Morag Grant. We also were incredibly happy to receive a large number of submissions for this inaugural issue (double what we were able to include!).

We are thrilled to present Issue No. 1 of MUSIC.OLOGY.EGA. Read it, share it, and discover a new facet of music research. And keep your eyes peeled for future issues; while we are graduating, MUSIC.OLOGY. ECA will continue to be part of the Reid School of Music.

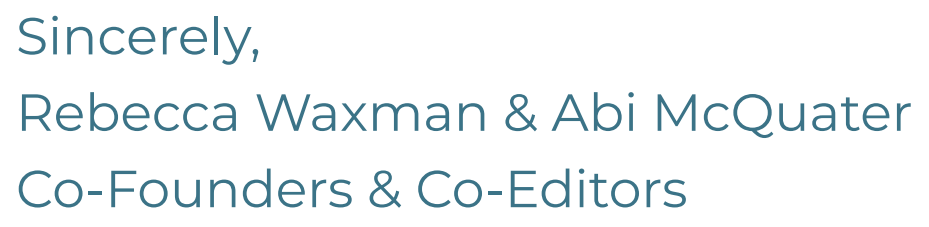

